\title{
In defence of digital contact- tracing: human rights, South Korea and Covid-19
}

\author{
Mark Ryan \\ Department of Philosophy, KTH Royal Institute of Technology, \\ School of Architecture and the Built Environment, Stockholm, Sweden
}

\begin{abstract}
Purpose - The media has even been very critical of some East Asian countries' use of digital contacttracing to control Covid-19. For example, South Korea has been criticised for its use of privacy-infringing digital contact-tracing. However, whether their type of digital contact-tracing was unnecessarily harmful to the human rights of Korean citizens is open for debate. The purpose of this paper is to examine this criticism to see if Korea's digital contact-tracing is ethically justifiable.

Design/methodology/approach - This paper will evaluate Korea's digital contact-tracing through the lens of the four human rights principles to determine if their response is ethically justifiable. These four principles were originally outlined in the European Court of Human Rights, namely, necessary, proportional, scientifically valid and time-bounded (European Court of Human Rights 1950).

Findings - The paper will propose that while the use of Korea's digital contact-tracing was scientifically valid and proportionate (albeit, in need for improvements), it meets the necessity requirement, but is too vague to meet the time-boundedness requirement.

Originality/value - The Covid-19 pandemic has proven to be one of the worst threats to human health and the global economy in the past century. There have been many different strategies to tackle the pandemic, from somewhat laissez-faire approaches, herd immunity, to strict draconian measures. Analysis of the approaches taken in the response to the pandemic is of high scientific value and this paper is one of the first to critically engage with one of these methods - digital contact-tracing in South Korea.
\end{abstract}

Keywords South Korea, Covid-19, Coronavirus SARS-CoV-2, European court of human rights, Pandemic surveillance, Technology ethics

Paper type Research paper

\section{Introduction}

The Covid-19 pandemic has proven to be one of the worst threats to human health and the global economy in the past century. There have been many different strategies to tackle the pandemic, from somewhat laissez-faire approaches, herd immunity, to strict draconian measures. In the early stages of the outbreak, many East Asian countries took rapid, stringent and pervasive measures, while European countries took more apprehensive, delayed and reactive responses. Despite the divergence in levels of effectiveness, there has been a clear absence of praise or even acknowledgement, of the achievements of East Asian countries during the outbreak. Some have pointed out the media's explicit bias and

(C) Mark Ryan. Published by Emerald Publishing Limited. This article is published under the Creative Commons Attribution (CC BY 4.0) licence. Anyone may reproduce, distribute, translate and create derivative works of this article (for both commercial and non-commercial purposes), subject to full attribution to the original publication and authors. The full terms of this licence may be seen at: http://creativecommons.org/licences/by/4.0/legalcode
International Journal of Pervasive Computing and Communications Vol. 16 No. 4, 2020 Emerald Publishing Limited $1742-7371$ DOI 10.1108/IJPCC-07-2020-0081 
IJPCC

16,4

arrogance in Covid-19 coverage, praising white, developed countries (such as Germany and New Zealand), while overlooking successful Asian responses (Samarajiva, 2020c).

The media has even been very critical of some East Asian countries' use of digital contact-tracing to control Covid-19. For example, South Korea [1] has been criticised for its use of privacy-infringing digital contact-tracing. However, whether their type of digital contact-tracing was unnecessarily harmful to the human rights of Korean citizens is open for debate. In response, this paper will evaluate Korea's digital contact-tracing through the lens of the four human rights principles to determine if their response is ethically justifiable. These four principles were originally outlined in the European Court of Human Rights, namely, necessary, proportional, scientifically valid and time-bounded (American Association for the ICJ, 1984; European Court of Human Rights, 1950; Morley et al., 2020; United Nations, 1966).

This paper will begin by briefly outlining Korea's response to the outbreak and how they used digital contact-tracing as one of their many tools to reduce transmission and death rates from Covid-19, before evaluating how their approach responds to the four principles outlined by the European Court of Human Rights. It will be divided into four main subsections to identify if their response meets these requirements and if not, how their approach should be changed to better accommodate them. The paper will propose that while the use of Korea's digital contact-tracing was scientifically valid and proportionate (albeit, in need for improvements), it meets the necessity requirement, but is too vague to meet the time-boundedness requirement.

\section{Korea's digital contact-tracing}

Following the MERS outbreak in 2015, the government amended their Infectious Disease Control and Prevention Act (IDCPA) to provide authorities with greater ability to collect and analyse data from infected individuals during outbreaks, whereby, private companies had to provide data to the Korea Centre for Disease Control and Prevention (KCDC) about their customers (Kim, 2020a). During the Covid-19 outbreak, this allowed the KCDC to effectively and quickly trace the previous locations of those infected and contact their contactees. This helped prevent the further transmission of Covid-19 (Golinelli et al., 2020). In addition to this method, the KCDC publishes data about all new infection cases on the government's website (Seoul News, 2020) (Figure 1) [2].

Figure 1 illustrates data derived from traditional contact-tracing, which involves face-toface interviews with individuals or over the phone. When traditional contact-tracing is sufficient, the data published on the government's website is minimal. If traditional contacttracing is unsuccessful, then a patient's global positioning system (GPS) information and card transaction logs are examined to identify their routes and potential contacts. South Korea's IDCPA allows authorities to assess the data of infected individuals from 27 public and private organisations as follows: 22 credit card companies, 3 telecommunications companies, the National Police Agency and Credit Finance Association of Korea (Pietrewicz, 2020). The KCDC can exclusively request information from telecommunications operators to identify infected individuals' routes and those likely to be infected by the virus (The Republic of Korea, Cheong Wa Dae, 2020, p. 41).

GPS data, times and locations and travel routes are mapped to determine the paths of infected individuals and modes of transportation used. The government uses cell phone data and satellite technology to do this (Chandran, 2020). "Local governments, in cooperation with the KCDC, quickly identified the movement path of the confirmed cases and informed the residents of the areas in real-time via mobile text message" (Shaw et al., 2020 p. 8). All 


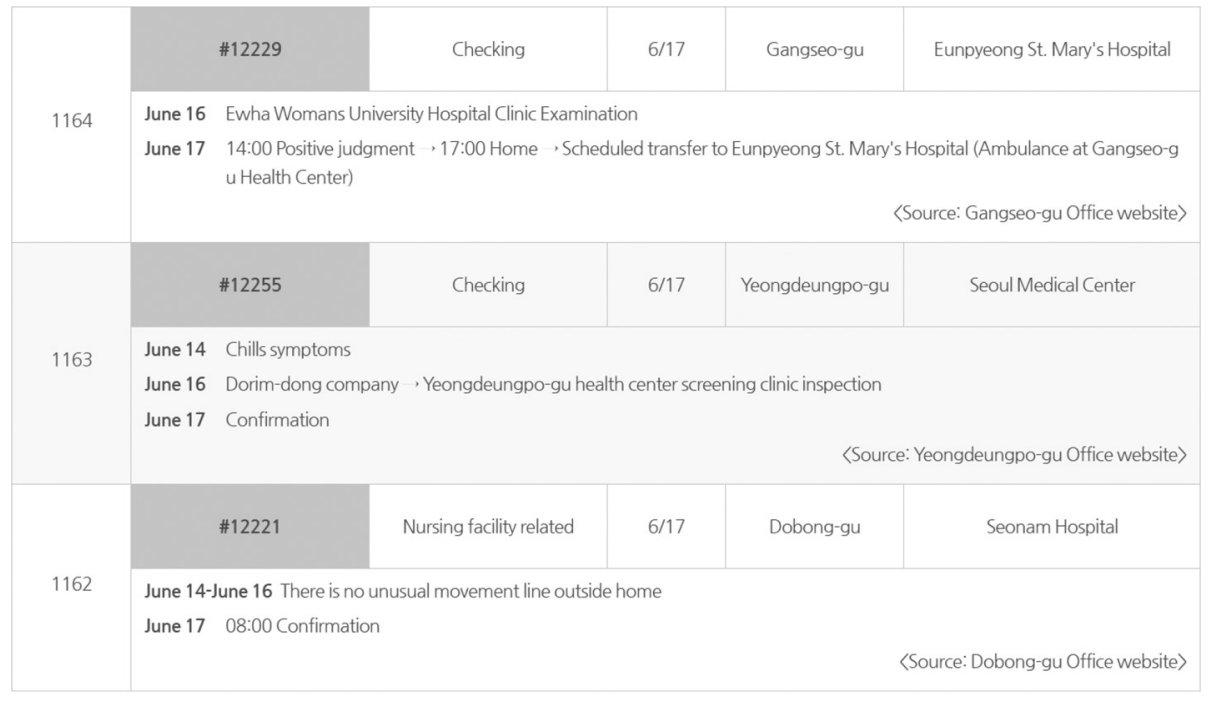

Source: Taken from http://news.seoul.go.kr/welfare/archives/513105 (accessed 18 June 2020)
Human rights

385

Figure 1.

Paths of three cases

personal identifiers are stripped before it is shared with the public through the government's websites. The individual's workplace and place of residence are also excluded.

Their travel route is shown from one day before they showed symptoms up to when they were tested and quarantined. This allows others to identify if they may have come into contact with the infected individual at these places, to implement precautionary steps before they become contagious and spread the virus to others and to initiate early self-quarantine procedures (Zastrow, 2020). Digital contact-tracing is only used if there is insufficient information from traditional contact-tracing and a more detailed description of the individual's movements is required and subsequently, published on the government's website (Figure 2).

The IDCPA states that the public has a right to know if they have been in contact with infected individuals - for their safety and those around them. There is a strong degree of transparency in the IDCPA's legislation, as they promptly disclose information about the movement paths and transportation used by the infected person. These notifications are specific and detailed: "Were you at the hot springs in the city of Yeongju at 5:30 p.m. on 17 February or a particular yoga class in Andong after 2 p.m. on 18 February? Were you at a singing class in Busan on 22 February or in Gimhae on bus 128-1 between 8:36 a.m. and 8:52 a.m. on 17 February"? (Kim, 2020f). The details published can range from:

Building: A specific floor or room and if a common arena, the specific time, specific store name, etc; Names of Stores: The names of stores and address; Public Transportation: Route number, vehicle number, embarkation and disembarkation times; If all individuals that had contact have been successfully identified, then the above information may not be made public (SeungCheol, 2020).

Korea created a centralised public database about infected individuals and their movements, which was used by app developers (through An application program interface) to identify the proximity of users to infected individuals. For example, the app Corona $100 \mathrm{~m}$ was designed to allow individuals to identify hotspots, rather than going through the abundance 


\section{IJPCC 16,4}

Figure 2.

Detailed path of case \#12186

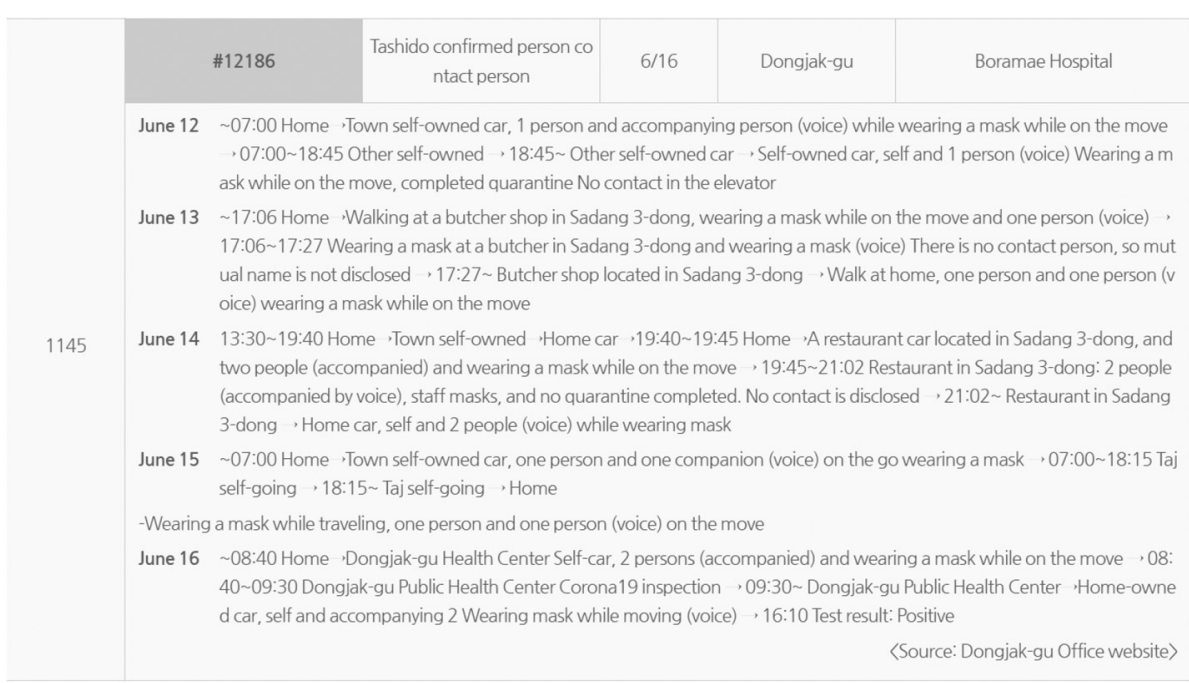

Source: Taken from http://news.seoul.go.kr/welfare/archives/513105 (accessed 18 June 2020)

of travel histories of individuals in the government database (Wray, 2020). The adoption of these apps has been relatively easy, with the high technological-focus in the country (e.g. 9 out of 10 Koreans have a smartphone) (Yonhap News Agency, 2019). However, the use of Korea's digital contact-tracing has come under scrutiny because of the potential for privacy infringements:

In some cases, the general public engaged in profiling and unveiled or inferred embarrassing personal details. Reidentification allegedly took place on a few occasions. Some of these individuals were affected by unwanted privacy invasion and even became subject to public disdain. Restaurants, shops and other business premises that infected individuals had visited often experienced an abrupt loss of business (Park et al., 2020, p. 2129).

These issues will be discussed later in this paper to identify if digital contact-tracing in epidemic responses is ethically justifiable or not. This paper is not intended to be used as a universal analysis for all types of digital contact-tracing, in all countries, in all situations. It is instead an analysis of a very specific case study, but in the hopes that it will lend insights into how digital contact-tracing can and should, be ethically used in crises response situations. It must also be made clear that Korea's digital contact-tracing is very different than the Bluetooth-enabled "corona apps" being deployed around the world at the moment, which will be discussed in Section 3.3 of this paper. Altogether, many countries are developing or using contact-tracing to combat Covid-19, so it is set to be a very important topic for discussion in the coming months and years (Figure 3).

\section{Ethics and Korea's digital contact-tracing}

There is no silver bullet for the control and mitigation of global pandemics. Until a vaccine is found, nations must work together and/or separately, to protect their citizens. Countries have implemented a wide variety of approaches to tackle Covid-19. There are many different viewpoints about what counts as a successful response to the outbreak. Some have proposed that harming the economy should be a last resort, others have tried to handle the pandemic 


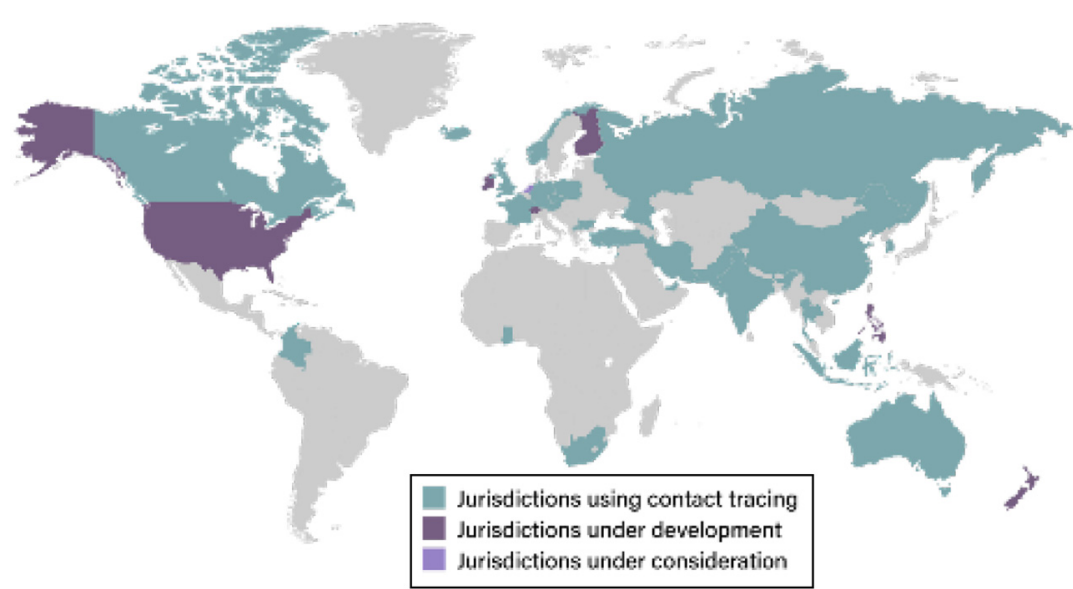

Source: Taken from www.nortonrosefulbright.com/en-kr/knowledge/publications/ d7a9a296/contact-tracing-apps-a-new-world-for-data-privacy (accessed 17 June 2020)

with minimal freedom violations, a few have attempted to implement herd immunity, but most have tried to actively prevent infections, people in ICU and deaths from Covid-19.

There have been many different approaches, but the methods and policies used have had a strong degree of overlap, often differing in degree, rather than kind: the use of facemasks (voluntary vs compulsory), testing (essential vs widespread), social gatherings (from 2 to 50 individuals), business closure (a few high-risk ones to all-but-essential) and contact tracing (manual vs automated). These policies have had an impact on individuals' rights, with some of the most obvious ones being privacy, freedom of movement, peaceful assembly and association [3]. Governments have tried to control the spread of the virus and protect "the right to life, liberty and the security of person” (United Nations General Assembly, 1948, Article 3).

However, there has been a great deal of tension between decision making and political action, and the level of rights' trade-off. One of the frameworks often used to address and respond to these tensions is the European Court of Human Rights (1950) four principles, namely, scientifically valid, proportional, necessary and time-bounded. I will analyse Korea's digital contact-tracing, during the Covid-19 outbreak, through the lens of these four principles.

\subsection{Scientific validity}

The incubation period for Covid-19 is between 5-6 days, on average (World Health Organisation, 2020). However, individuals can be infectious, without having symptoms, during this period. Therefore, being able to identify, track, test and quarantine those who are infected early is important. When someone tests positive for coronavirus, health workers retrace their steps, to inform their contacts to be tested or quarantined - otherwise known as contact-tracing:

Isolating one single case can prevent a whole chain of future transmissions. This is why tracing, isolating and testing people for coronavirus is essential for reducing the reproduction rate ( $\mathrm{R}$ rate) 


\section{IJPCC}

16,4

\section{8}

Figure 4.

What is contact tracing?

\section{WHAT IS CONTACT TRACING?}

An alternative to prevent long term lockdowns or overwhelmed health systems

As far as COVID-19 cares, there are 3 kinds of people:

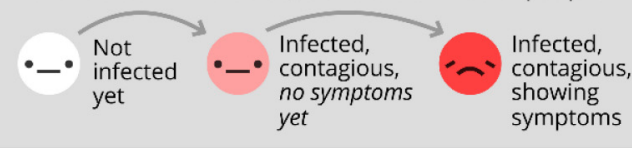

If we do nothing, here's what happens to a neighborhood with one Patient Zero:

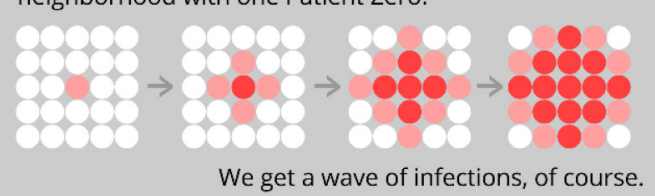

Here's what happens if, when someone finds out they're infected, they immediately self-isolate:

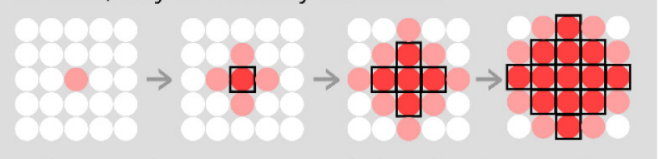

Alas, people are contagious before showing symptoms! We're one step behind the virus.

But here's what happens if, when someone finds out they're infected, they and their close contacts self-isolate:

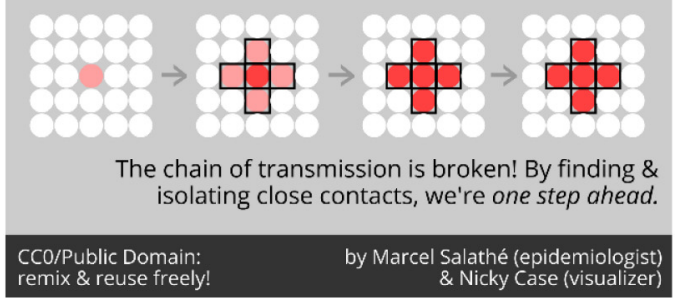

across a population. Although it's impossible to find all cases, the more cases that are contacttraced, the more the $\mathrm{R}$ is driven down (Neal, 2020) (Figure 4).

Traditional contact-tracing originated in the 19th century to identify the contacts of those infected. It is effective because "unidentified infections are most likely to be found amongst contactees, and efficient because the resources can be directed towards individuals at risk only" (Klinkenberg et al., 2006, p. 1). Contact-tracing can identify infected individuals before they develop symptoms and can "prevent onward transmission from the secondary cases" (Keeling et al., 2020, p. 1). Contact-tracing has proven to be an effective method to counter many diseases, such as the SARS outbreak, AIDS and typhoid (Bell, 2020). Contact-tracing has evolved and we have seen the deployment and use of digital contact-tracing during the 
Covid-19 outbreak. In Korea, the KCDC can request data from 27 organisations to map the times, locations and movements of individuals infected with the virus if traditional contacttracing is insufficient. This process allocates resources and testing more efficiently to those more likely to be infected, moving testing from a diagnostic approach to a preventative one because:

[i]solation and contact tracing can be an effective means to slow down epidemics, but only if the majority of cases are ascertained. In a situation with social distancing, contact tracing can act synergistically and tip the scale towards containment (Kretzschmar et al., 2020, p. 3).

One of the significant problems in many countries is that they are unable to identify who has the disease, who they may have given it to and how the disease is spreading. If countries cannot, and do not, implement effective contact-tracing at the start of an outbreak, it can have devastating effects on the spread of the disease. This has been clearly illustrated in practice:

[...] "those countries which persisted with expanded and rigorous testing and tracing programmes, such as Germany, South Korea, Hong Kong, Singapore and New Zealand, have fared better with lower deaths rates than those which did not, such as Belgium, France, Italy, Spain, UK and the USA" (Whitworth, 2020).

Traditional contact-tracing is a tried-and-tested method for controlling the spread of infectious diseases because effective testing "is at the heart of the country's coronavirus strategy" (Fleming, 2020). It has been used for over a century, but digital contact-tracing is a new method that is claimed to provide an improved speed of information, location and contact accuracies. In Korea, digital contact-tracing was only used when traditional contacttracing proved limited. For example, when there is not enough information, the patient's memory is unreliable or their contacts were too abundant to track down manually (Figure 5).

Cases are allocated into three groups as follows: confirmed infected cases, suspected cases who were directly in contact with confirmed cases and patients under investigation (PUI). The suspected cases are identified through traditional contact-tracing, while PUIs can be associated with a cluster outbreak of potentially-infected individuals (Samarajiva, 2020a). However, "[t]here is no legal criteria for identifying "potential" patients or "persons feared to be infected"” (Kim, 2020a). Korea uses the WHO's guidelines on close contacts/potentially infected individuals, namely, someone who: cares for an infected individual without appropriate PPE; has been in close or intimate settings recently, such as family, friends,

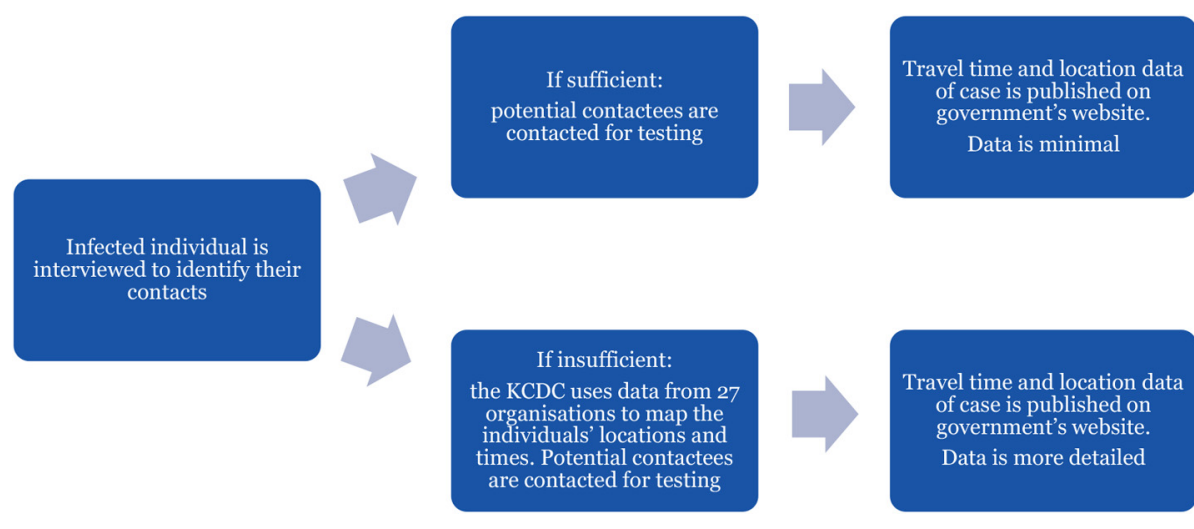

Human rights

389

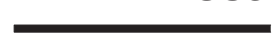


IJPCC

16,4

390

school or the workplace; and someone who has been within $2 \mathrm{~m}$ of the infected individual for over $15 \mathrm{~min}$ (CDC, 2020).

However, defining potential contacts of the infected individual is extremely difficult when there is a large cluster outbreak. In many instances, the KCDC was able to identify individuals through their registration details, card details, seating locations and so forth. For example, if an infected individual went to the cinema, the KCDC can identify their seat choice and those sitting around them through their purchase and credit card details. When there is a larger outbreak, such as in the Itaewon district, the KCDC was able to identify and contact individuals because they provided their details before entering bars and nightclubs. They also worked with telecommunication companies to identify who was in the district that weekend, resulting in 45,000 people being tested (Woodward, 2020). While cumbersome and resource-intensive, this approach ensured the control of this potentially huge outbreak.

However, the success or failure of digital contact-tracing is not only based on the technology's scientific effectiveness but also on a country's ability and resources to act upon this information. For example, a country needs to have sufficient testing kits, professionals to carry out tests, resources to analyse samples in a timely fashion. Otherwise, many of the benefits derived from digital contact-tracing will be lost. Korea implemented widespread testing, set up walk-in and drive-through tests and provided results to individuals within a few hours (Fisher and Sang-Hun, 2020). "Korea does not have a tech solution, they have a solution that uses tech" (Samarajiva, 2020b). The effectiveness of digital contact-tracing is reliant on the ecosystem that it is being deployed and the competence of the government.

\subsection{Proportionality}

Proportionality describes if action is justified and the benefits outweigh the harms. A proportionate response is appropriate to the situation. While disproportionate actions are unnecessarily excessive. Hurka's $(2005,2008)$ proportionality in war states that benefits should be weighed from goods that are present in the cause for going to war. This avoids the utilitarian conclusion of weighing up all possible benefits, which can lead to repugnant conclusions, such as the justification of war for "economic benefits, morale boosters or even entertainment" (Macnish, 2015, p. 534). While these "peripheral benefits" may be accrued, they should not be used in the measurement of proportionality (Macnish, 2015). For example, when applied to digital contact-tracing, improving the technology or the employment of people cannot be justifications for implementing it. This section will outline the benefits and harms of Korea's digital contact-tracing, using Hurka and Macnish's criteria.

3.2.1 Benefits of Korea's digital contact-tracing. During the early period of an outbreak, it is uncertain how it will spread, how badly your country will be affected, your casualties and socio-economic impacts. Therefore, one cannot weigh up every impact, only those that are somewhat reasonably foreseeable. It is often difficult to determine the likelihood of impacts, thus making it challenging to evaluate the correct proportionality. In the case of Covid-19, the most obvious benefit of implementing digital contact-tracing is the containment of the virus, avoiding lockdown and most importantly, the protection of human life. If a country does not act swiftly, clearly and with effective purpose, an epidemic will wreak havoc on one's healthcare system and cost lives. If Korea did not enact any anticontagion policies, it is predicted there would have been 5 million cases in the country (Hsiang et al., 2020). In the early stages, the case fatality rate was unclear, but if it was similar to the SARS-CoV outbreak in 2002-2004 (i.e. 11\%), this would have caused 500,000 deaths in the country. 
Korea did not have the benefit of hindsight and it had to act swiftly. It is worth comparing Korea's response and outcome with a similar country, but one that took different actions (Spain). Both Spain and Korea have a similar population size, gross domestic product (GDP), infrastructure, epidemic/pandemic preparedness [4], high elderly populations and both witnessed strikingly similar early Covid-19 statistics early on in the outbreak. Both countries were on very similar trajectories, but the early actions by the KCDC caused strikingly different outcomes (Table 1).

One of the reasons for Spain's high infections and death tolls was because the government refused to close down large events at the start of the outbreak [5]. On $8^{\text {th }}$ March when Northern Italy was deemed a quarantine zone, the Spanish Government allowed 120,000 people to gather for International Women's Day and football matches with 60,000 spectators (McMurtry and Zampano, 2020). A week later, the country was in lockdown (15th March) [6] and this lasted for over three months (Jones and Willsher, 2020). The lockdown forced people to stay at home, with the exception to buy food, medicine, go to work or emergencies. This was actively enforced by over 240,000 police, 2,500 military and drones, all being deployed to stop, question and sanction individuals to ensure compliance (Ward, 2020).

Korea avoided Spain's large death toll, the psychological impact of lockdown, high unemployment rates, increased debt and a possible recession. While digital contact-tracing is not the sole outlier, it certainly contributed to Korea being able to conduct effective testing and control the early spread of the virus, which was not available in Spain. Also, Korea witnessed a comparatively low death rate because of early detection and treatment, access to healthcare, hiring extra doctors and opening hospitals for public use (Dowd et al., 2020; Hauser et al., 2020; Son et al., 2020). The KCDC provided information to the public about how to protect themselves (Shaw et al., 2020).

The first few weeks of a country's response to an epidemic is vital. It must effectively test individuals, trace their contacts and quarantine the infected. The importance and benefit of digital contact-tracing are the most effective at the beginning of an outbreak when numbers are still at a manageable level and it can identify and control clusters. If numbers explode beyond a certain threshold, contact-tracing would be very difficult and may still force a country to implement lockdown (Kim, 2020c). However, the effectiveness of a country's digital contact-tracing will largely depend upon their holistic outbreak response and the other measures being taken to support it. Digital contact-tracing should not be seen as a

\begin{tabular}{|c|c|c|}
\hline Information & South Korea & Spain \\
\hline Population & 51.6 million & 47 million \\
\hline GDP per capita in $2018^{\mathrm{a}}$ & $\$ 31,363$ & $\$ 30,524$ \\
\hline Daily new cases - Day $1^{\mathrm{b}}$ & 34 (20th February) & 28 (1st March) \\
\hline Daily new cases - Day 10 & 909 (29th February) & 772 (10th March) \\
\hline Daily new cases - Day 27 & 84 (17th March) & 9,181 (27th March) \\
\hline Total Cases ${ }^{c}$ & 11,225 & 282,480 \\
\hline Total Deaths ${ }^{\mathrm{d}}$ & 269 & 26,837 \\
\hline Lockdown & None & Three months \\
\hline
\end{tabular}

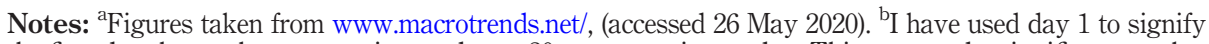
the first day that each country witnessed over 20 new cases in one day. This was used a signifier to mark a crucial turning point in the countries. Data taken from: https://ourworldindata.org/ (accessed 29 May 2020). 'Taken from: www.worldometers.info/coronavirus/ (accessed 26 May 2020). ${ }^{\mathrm{d}}$ Taken from: www. worldometers.info/coronavirus/ (accessed 26 May 2020)

Human rights

391 
IJPCC

16,4

panacea for a country's outbreak, but simply one tool in an otherwise effective arsenal of responses.

3.2.2 Harms caused by Korea's digital contact-tracing. Macnish (2015) outlines 12 potential harms that often arise from the use of surveillance [7]. However, only three of these are relevant for the use of digital contact-tracing in Korea, namely, privacy violations, social sorting and abuse of power.

3.2.2.1 Privacy violations Korea has stringent privacy protection laws, such as its 2011 Personal Information Protection Act (PIPA). This "bans the collection, use and disclosure of personal data without the prior informed consent of the individual whose data are involved" (Park et al., 2020, p. 2129). PIPA was altered after the Middle East respiratory syndrome (MERS) outbreak in 2015 to allow authorities to override some of these provisions in future epidemics. The government realised that the strict criteria found within PIPA were a barrier to their response during the MERS outbreak. As a result, Korea "established a clear legal basis for collecting personal data during disease outbreaks that align with general data protection regulation guidelines" (Kim and Kim, 2020).

When using digital contact-tracing, we can assume that not everyone will consent to their data being accessed and used. However, this may also occur for traditional contacttracing, whereby, an individual does not comply, for whatever reason, to disclose who they have come into contact with. Unless one is tricked or tortured, they can successfully refrain from providing this information if they want to. However, with digital contact-tracing, the KCDC may directly access their digital movements, thus, creating concerns around consent. Digital contact-tracing has been used for approximately $35 \%$ of all cases in Korea (or 4,000 citizens) [8]. In a recent survey, most Korean citizens said that they prefer the protection of the public good over individual rights (Zastrow, 2020). Approximately, 80\% of Koreans said that they would accept some privacy infringements to fight the epidemic (Pietrewicz, 2020). This would still leave several individuals who would not consent to its use.

Secondly, the information published on the government's website from digital contacttracing is detailed and has the potential for privacy infringements (Figure 2). If information is too specific, it may allow individuals to be identified and outed, causing psychological harm to the individual, harassment or create relationship problems (Jo, 2020): "Some people would connect the dots thinking, wait a minute, I know someone who's 58 years old, who lives in this area, who is a banker. "You had cases where people were in places they shouldn't have been in such as hotels and motels"” (Coffey, 2020). Early in the outbreak, Korea's National Human Rights Commission (NHRC) stated that some of the KCDC's notifications were unnecessarily intrusive and their methods of disclosure should be amended (Eui-rae, 2020; National Human Rights Commission of Korea, 2020).

3.2.2.2 Social sorting - Stereotyping, stigmatisation and discrimination There has been a concern about "outing" patients, false identifications, witch-hunts and abuse towards those who spread the virus (Jo, 2020). While digital contact-tracing cannot be held responsible for all of these harms, it could be claimed that it has contributed to or exacerbated, existing stereotypes, discrimination and stigmatisation in Korea, namely, against the Shincheonji Church and the Lesbian, Gay, Bisexual, Transgender/Transsexual plus community.

At the start of the outbreak, a large increase in cases was caused by a super-spreader from the secretive Shincheonji Church [9]. The super-spreader brought the virus back from China, infecting many people, resulting in greater hostility towards the Church (Shim et al., 2020). The Church is known for its close personal contact, street canvassing, attendance mass when sick and prohibiting face masks in Church, which all contributed to the spread of the virus (Chung, 2020; Sang-Hun, 2020; Seibt, 2020). Members also refused to cooperate with officials when they tried to contact them (Kim, 2020b). This contributed to a huge spike in cases, reaching 7,382 by 
9th March, with the Church accounting for 61\% of them (Huang et al., 2020a; Mizumoto et al., 2020; Kang, 2020; Dudley and Lee, 2020). By 21st April, 48.8\% of all cases in the country were the result of this cluster outbreak (i.e. 5,212 cases) (Statista, 2020).

The Church is known for its privacy and encourages members to keep activities secret for fear of reprisal and stigmatisation within Korean society. As a result, members often refused to cooperate with Korean authorities, lying about their membership, attendance of masses, locations and identities (Lee, 2020; Normile, 2020; Sang-Hun, 2020). Many blamed the Church, saying that if it had "not refused to provide the names and contact information of its members and blocked journalists' efforts to decipher spread of the virus in its ranks, lives in that country might have been spared infection, illness and death" (Garrett, 2020, p. 943). As a result, members have been shouted at in public, lost their jobs, received death threats and some have even taken their own lives (Sang-Hun, 2020). A $28^{\text {th }}$ February survey showed that $86.2 \%$ of Koreans were in favour of a search and seizure of the Church if they did not cooperate (Realmeter, 2020). In total, 1.5 million citizens signed a petition to dismantle the Church altogether (Kim, 2020e).

In early May, it looked like Korea was going to have a second-wave of Covid-19 following an outbreak in the Itaewon district in Seoul. Itaewon is a vibrant district full of bars, nightlife, an ex-pat community and is a hub for the LGBT+ community. This outbreak was caused by a 29-year-old male partying in the district on $1^{\text {st }}$ May [10]; resulting in 100 new cases (Hui, 2020). Within two weeks, this number spiked to 257 cases (Cox, 2020). In an attempt to curb the virus, officials tracked down and tested 46,000 people (Woodward, 2020). "As of 20 May, there have been 336 new cases of Covid-19, as the beginning of the month, a far cry from February when there were more than 3,000 in just two weeks" (Cox, 2020).

While the KCDC's use of digital contact-tracing was able to control the outbreak, it also raised several ethical concerns. Due to the area's association with gay clubs, many people did not come forward to be tested. The country is conservative about sexuality and there is a lot of discrimination towards the gay community. Many people keep their sexuality hidden and if they had to quarantine because of this outbreak it may "out" them. While homosexuality is not illegal in Korea, some stated that if they were outed, they risk losing their jobs, friends and family (Kim, 2020d).

3.2.2.3 Abuse of power/function creep There are concerns that digital contact-tracing will be misused to implement unnecessary surveillance on citizens (Muller et al., 2020, p. 4). There is a fear that digital contact-tracing will lead to 24/7 tracking and monitoring (Mauro, 2020). There is the potential that digital contact-tracing will be repurposed for other activities that it was not originally designed for. Many surveillance methods in the past were originally implemented for very specific and time-sensitive reasons but were subsequently used for nefarious purposes. It is important to clearly identify what the Korean Government can do with this technology, the data retrieved and how Korean citizens are protected from abuses of power as a result of its use.

3.2.3 Proportionality: balancing benefits and harms. Many have criticised Korea's use of digital contact-tracing, implying that letting people die is a more preferable option than using surveillance technologies: "The rest of the world will probably take the virus over the cure" (Babones, 2020). To make this clear, taking the virus implies accepting overburdened healthcare systems, economic recessions, travel restrictions, lockdowns, illnesses and ultimately, premature death of thousands of citizens. There is a wide divergence in cultural and societal acceptance of digital surveillance, with many Western countries opposing these measures, viewing them as too intrusive. For some, this kind of governmental interference in our private lives is wrong, no matter what. This has led some to question the emphasis the West places on privacy: 
IJPCC

16,4

For Western democracies, the time has come to either rethink our values around the tradeoff between personal privacy and public safety in a pandemic or to accelerate technology innovation and policy development that can preserve both (Huang et al., 2020b).

In contrast, many East Asian countries have accepted there may be some privacy trade-offs for the public good (Kasulis, 2020). The Korean Government stated that, despite their best efforts, privacy infringements may still occur. However, during pandemics, they "should prioritise public safety or public health before privacy" (Ministry of Land, Infrastructure and Transport, 2020). Many Koreans are also aware of this and "locals remain largely unopposed to the incursion into their private lives, with one saying: "Koreans pride their safety over their privacy"' (Coffey, 2020).

The Korean Government has promoted transparency during the outbreak, publishing their findings and sending text notifications about how citizens can protect themselves. Their approach has received $89.1 \%$ of support from the public: "The transparency with which the government has adapted its surveillance practices inspired public trust in an endeavour that would otherwise have aroused suspicion" (Jo, 2020). Despite the favourable views from the general public, it does not mean that the government has not and should not, care about privacy. For example, the NHRC recommended stronger privacy protection for individuals by "aggregating all patients' footprints over time and redacting individualspecific information on age and gender" (Jo, 2020). The KCDC incorporated these insights and updated its guidelines in less than a week, with three main changes (14th March):

[...] the logs should be time-limited from one day before the symptoms occurred until the date of quarantine (or if asymptomatic, one day before the quarantine); the range of contacts traced should be determined based on the patient's symptoms, exposure conditions and timing; and "personally identifiable information" - including work and home addresses - should be excluded in public disclosures (Jo, 2020).

The KCDC only collects essential data, they ensure that access is limited and their platform runs on a private and well-secured network (The Republic of Korea, Cheong Wa Dae, 2020, p. 45). The KCDC manages personal data according to existing legal requirements by incorporating VPNs, exclusive log-in systems, dual firewalls and a strong cybersecurity system (Ministry of Land, Infrastructure and Transport, 2020). The data retrieved is retroactive of previous days, rather than using real-time data. The Korean Government also claims that "there has been no damage suffered by infected individuals as a result of their travel history being made public. It is very difficult to identify an individual with just that information" (SeungCheol, 2020).

However, there may still be individuals who do not consent to the use of their data, regardless of the privacy-protecting measures in place. The KCDC appear to implicitly accept that there may be individuals who do not consent to their data being used, but that this may need to be overridden in pandemics for the public good, making some uses of their digital contact-tracing a form of surveillance. Surveillance is typically classified as the "monitoring of a competent adult or adults over a period of time without their consent" (Macnish, 2015, p. 530). Alternatives to this type of surveillance will be compared in Section 3.3.

Concerning social stigmatisation; unfortunately, this is something that has occurred throughout the history of medicine and also, traditional contact-tracing. "In the 1980s in Australia, it was used to identify at-risk communities at the start of the AIDs epidemic and gay men bore the brunt of conservative politics, religious backlash and stigma" (Bell, 2020). Some groups were stigmatised, stereotyped and discriminated against in the use of digital contact-tracing in Korea. The KCDC should have pre-empted the possibility that the virus 
would cluster within vulnerable groups and communities. Greater attention needs to be placed on identifying these groups, how information can be carefully disseminated and ways to avoid these harms from occurring.

Greater efforts and technical measures could also be made to ensure that these groups are better protected. For example, one way to dissociate individuals from cluster outbreaks and to ensure they are not stigmatised is to conduct lottery-style randomised testing within a population. Individuals could, therefore, claim they were not part of the cluster outbreak but were being tested/quarantined as a result of the lottery testing. This is certainly room for further research into technical and policy-oriented ways to protect vulnerable groups from being stigmatised through digital contact-tracing.

There also needs to be clear parameters of where and how these techniques can be used. In Korea's case, function creep should not be possible because of the stringency of their privacy laws (PIPA). These regulations only permit limited access to data when responding to events such as the Covid-19 outbreak. The KCDC has exclusive access to this data, but it has to request it from the police and it is not available after the outbreak. Digital contacttracing must be used for the sole purpose it was created: the identification of Covid-19 cases and the control of the epidemic. This is vital for the justifiability of proportionality while avoiding its repurposing or misuse.

\subsection{Necessity}

The necessity requirement states that if there are less intrusive methods available for achieving the same ends, then these alternatives should be taken (Bock et al., 2020). The ends of Korea's digital contact-tracing is to identify contacts of an infected individual to reduce the transmission rate of the virus. This is done for the overarching end of protecting life, public health and liberties. This is achieved by curbing the spread of the virus, easing pressure on the healthcare system and minimising the harmful economic impacts of lockdowns, business closures and travel restrictions.

Governments must choose from multiple options that have varying levels of effectiveness and intrusiveness. If there are less intrusive measures available, the test of effectiveness should still be applied to these alternatives (Gerards, 2013). For example, a measure may be more effective, but far more intrusive; while others maybe not only less intrusive but also less effective (Gerards, 2013). While it is ideal to implement approaches that are the least intrusive and most effective, this is not always straightforward in practice. It is also very difficult to estimate in risky and uncertain situations, such as pandemics. Unfortunately, sometimes there has to be a trade-off between effectiveness and intrusiveness. However, determining which one has greater importance is highly contested and will be discussed in this section.

3.3.1 Replace with the lockdown. Some propose that lockdown can achieve the same ends as, but is a less intrusive method than, digital contact-tracing. It is estimated that lockdowns have helped to reduce the spread of Covid-19 infections by between 75-87\% (Gayle et al., 2020; Flaxman et al., 2020). Their effectiveness is unquestionable, but whether they are less intrusive than digital contact-tracing is debatable. A recent German data protection impact assessment indicated that a lockdown is a preferable option to digital contact-tracing because " $\mathrm{n}] \mathrm{o}$ individual personal data are required for the general verification of compliance with curfews" (Bock et al., 2020, p. 59). However, should personal data be the sole determinant for intrusiveness? Are lockdowns a less intrusive method than digital contacttracing?

By 5th April, 90 countries had gone into some form of lockdown, accounting for 3.9 billion people globally (Sandford, 2020). Currently, Korea is one of the few countries that has 
IJPCC

16,4

still avoided lockdown. Lockdowns have varied in range and severity. Some of the human rights harm seen throughout lockdown range from countries implementing a traffic-lighted system for individuals' access to resources (China), spraying migrants with chemicals (India), death threats for breaching curfew (Philippines), public degradation (Paraguay), police brutality (South Africa), being beaten to death for not wearing a mask (Mexico) and being killed for lockdown breaches (Nigeria, Kenya, Rwanda and Uganda) (Agren, 2020; Kola, 2020; Mugabi, 2020; Ratcliffe, 2020).

If we look at some of the less extreme cases, lockdowns still breach many of our human rights: police and drones to ensure lockdown compliance (Article 12: protection of privacy), stay-at-home orders (Article 13: the right to freedom of movement), church closures (Article 18: the right to practice one's religion), restrictions on visiting people in healthcare facilities (Article 20: freedom of association), limiting access to healthcare (Article 21: equal access to public services), the closure of businesses (Article 23: the right to work), closure of gyms, social clubs and restrictions on larger gatherings (Article 24: the right to rest and leisure) and school closure (Article 26: the right to education) (United Nations General Assembly, 1948). There is also a direct link between lockdowns and increased incidences of domestic violence, suicide and mental health issues (O'Hagan, 2020; Joseph, 2020).

The main rights' concerns with digital contact-tracing are privacy infringements and social stigmatisation, which are also caused by lockdowns. Many of the rights infringements caused by lockdowns are also far more intrusive and harmful than digital contact-tracing. It is difficult to see how the extensive list of human rights infringements during lockdown is comparable to those of digital contact-tracing. Korea's digital contact-tracing is not being used on everyone, like privacy infringements during a lockdown. It is unreasonable to propose that the quantity and range of direct and actual humans rights infringements caused by lockdowns are less intrusive than the [mostly] potential and indirect harms caused by temporary, limited and minimal digital contact-tracing use, as demonstrated in Korea.

3.3.2 Replace with Bluetooth "corona apps". Many of the Bluetooth-enabled apps being released are voluntarily downloaded and notify individuals if they are within X distance of someone with the virus for the $\mathrm{X}$ period (De Ingenieur, 2020). The distance from the infected individual and the period varies amongst countries and apps. Altogether, digital contacttracing is relatively new, but it is being implemented in several countries, from Singapore, Australia, India and throughout Europe (Klonowska, 2020, p. 8). Decentralised and voluntary contact-tracing apps are being promoted as the least intrusive form of digital contact-tracing, particularly those that have gone through stringent data protection assessments, overcoming the consent issue earlier.

However, corona apps are often dependent upon several specific requirements for them to be effective: you have a smartphone, you have the software downloaded, Bluetooth enabled, have your phone with you most of the time, most others do the same (particularly those with the virus), people self-isolate after being notified and the device works effectively at identifying when you are in close contact with those infected (De Ingenieur, 2020). One issue is determining how long one should be in the presence of an infected individual before being notified. Should the device warn you if you have been in any kind of contact at all, $15 \mathrm{~min}$ or $20 \mathrm{~min}$ ?

There is a concern that having time-specific warnings may lead individuals into a false sense of security because they have not been warned of a threat by their app (Babones, 2020). Furthermore, because of the divergent levels of acceptability and usability, digital contact-tracing apps may lead to a digital divide within countries, due to varying levels of smart-phone use, internet use and technological-savvy (for example, $43 \%$ of the EU population has insufficient levels of digital skills) (Floridi, 2020; Taddeo, 2020): 
Many people may choose not to download the app, not have enough storage, may be unable to use the app due to dated mobile phone versions, may have insufficient battery power to support constant Bluetooth activation, kids and senior citizens (in the highest-risk group) may not be carrying or even own a personal smart device. In Singapore, two weeks after launching, the use of the app was still significantly under the necessary threshold at about 12\% (Klonowska, 2020, p. 9).

Corona apps require the uptake of at least $60 \%$ of the population for them to be effective; however, a much higher level is desirable (Gilbert et al., 2019, p. 175) [11]. As most of these apps are voluntary, their adoption has often been low. Of course, some countries have implemented mandatory corona apps, which would overcome some of these issues but would rescind the benefits of voluntariness and consent. Furthermore, there are technical issues with these apps. Establishing connections between two devices is often difficult and dependent upon the device itself, its connection and signal interferences. This may give the user false positives or negatives, leading to individuals being infected or unnecessarily selfisolating. Essentially, Bluetooth technology is not fit-for-purpose: "As Bluetooth can't actually be used reliably to measure distances, these [distance proximity] figures suggest an illusory precision" (Babones, 2020).

Bluetooth-enabled apps are technically problematic, but some of them have also been shown to be ethically lacking, as well. For example, Norway's data protection authority stated that their use of digital contact-tracing was creating a disproportionate intrusion on individuals' privacy (Garthwaite and Anderson, 2020). It was discontinued because of the low levels of use, its ineffectiveness and because of privacy invasions (Agence France-Presse in Oslo, 2020). The level of ineffectiveness and the way that they are being implemented, does not make corona apps a suitable alternative to Korea's digital contact-tracing, despite being, arguably, less intrusive (if they abide by privacy regulations are voluntary and implement decentralised processing of data).

Korea's pervasive approach towards potential infections, as shown in the Itaewon example, is unparalleled in identifying infected cases within a cluster outbreak. It is far more effective at addressing cluster outbreaks than corona apps because it identifies and tests all possible contacts of the infected individuals, while also providing information to warn any additional individuals not identified, through their online and SMS updates. If technology improves and corona apps overcome many of their technical flaws, then they offer a potential solution or combined solution, with Korea's digital contact-tracing approach.

3.3.3 Replace with traditional contact-tracing. Some have proposed that traditional contact-tracing is a more ethical way to achieve the same ends as digital contact-tracing. A position that is being put forward in the debate is to hire more staff for traditional contacttracing (Muller et al., 2020). Traditional contact-tracing is limited in several ways, where digital contact-tracing can be of benefit. To stop the spread of Covid-19, it is essential to identify, test and quarantine those suspected of having the virus at an early stage before transmission occurs. Traditional contact-tracing can often achieve this but is severely limited by the length of time and resources to trace the steps of those infected, identify their contacts, track them down and test them. It relies on the memory of the infected individual, the ability to contact infected individuals and the speed to conduct tests and provide results (Klonowska, 2020).

Speed and efficiency are essential when controlling contagious outbreaks. One measure is to test those who are not yet showing symptoms. For example, pre-symptomatic cases on the Diamond Princess accounted for $52 \%$ of those infected, and many studies estimate that between one third and one-half of all Covid-19 transmissions occur from pre-symptomatic cases (Ferretti et al., 2020). Also, up to $40 \%$ of transmissions are caused by asymptomatic 
IJPCC

16,4

individuals - individuals with the virus but who do not show symptoms (Boseley, 2020). Traditional contact-tracing is often ineffective to respond to these cases because of the speed at which it has to be implemented and the urgency of contacting these cases (Gilbert et al., 2019).

If we use faster, more efficient and accurate contact-tracing, it would provide a greater opportunity to control it. In the case of Korea, manual tracing would have taken officials $24 \mathrm{~h}$ to track down the contacts from only one case, but automated tracing can do it in $10 \mathrm{~min}$ (The Republic of Korea, Cheong Wa Dae, 2020, p. 45). This dramatically reduces the workload of overburdened human contact-tracers, reduces contact tracing times and allows swifter responses to control the outbreak. It allows individuals to be contacted quickly before the onward transmission to others, particularly, those caused by asymptomatic and pre-symptomatic cases.

However, it must be made clear that digital contact-tracing needs to be combined with efficient traditional contact-tracing to fulfil its effectiveness (Cohen et al., 2020). The KCDC uses traditional contact-tracing and implements digital contact-tracing when it is fundamentally necessary. Traditional contact-tracing allows for identifying when digital contact-tracing should be implemented and avoids issues around solely automating all contact-tracing responses. Essentially, digital contact-tracing is implemented when traditional contact-tracing is insufficient.

3.3.4 Replace with another anti-contagion method. When it comes to outbreaks, national approaches are multifaceted. No country relies on only one method. Therefore, it is very difficult to pinpoint the success of individual methods because their outcomes and effectiveness cannot be extracted from the myriad of responses in place. As Sweden's Chief Epidemiologist, Anders Tegnell, notes: “The problem with that is that you don't really know which of the measures you have taken is most effective" (Henley, 2020). Most countries have recommended a range of anti-contagion methods: physical distancing, the use of face masks, reduced group gatherings, travel restrictions, protecting the vulnerable, school closures and improved hygiene standards (albeit, to different degrees) [12]. However, when countries have witnessed rapid daily increases in infection rates, these approaches alone have often been insufficient. As Tegnell noted, Sweden followed these recommendations, but "what else, besides what we did, you could do without imposing a total shutdown” (Henley, 2020).

Except for a vaccine, countries have to initiate responses that they deem credible and necessary from the range of methods at their disposal. Even with the development of a vaccine, this may not be enough (for example, $16 \%$ of British citizens said they would refuse a vaccine) (Hern, 2020). Altogether, anti-contagion responses are not implemented alone but act as part of a larger strategic response [13]. None of these methods can achieve the primary goal of digital contact-tracing, namely, to effectively trace the previous locations of infected individuals and warn contacts to be tested. They are not designed to do this, so it would be unfair to expect them to.

However, one may argue that some of these mitigation strategies are more effective at achieving the overarching goal of digital contact-tracing, namely, the reduction of cases, deaths and people in ICU. While many of the Covid-19 methods are effective for their given task, it is somewhat unfair to compare them as replacements. For example, face masks are designed to primarily keep respiratory droplets of infected individuals from spreading to others, and secondarily, to provide some protection for non-infected users. Therefore, it would be unusual to promote face-masks as a replacement for social distancing, good hygiene practices or reduced group gatherings. In the context of digital contact-tracing, there needs to also be additional steps in place for when preventative measures do not work 
and there is an onward transmission. Governments need to implement both preventative and remedial measures.

While measures, such as the use of face masks - which has been encouraged and used throughout Korea - may, arguably, be less intrusive, they cannot altogether replace contacttracing. In an ideal world, where face-masks are fully effective and effectively used, they would eliminate the need for contact-tracing. The KCDC supports this, but it is not a reality we currently face. Essentially, digital contact-tracing cannot be replaced by face-masks or other individual anti-contagion preventative strategies because of their different roles. Furthermore, Korea's digital contact-tracing only becomes implemented when there are cases, and there $i$ an outbreak. It ceases to exist when the outbreak stops. It is not used if there are no cases. Therefore, other anti-contagion strategies can nullify the need for digital contact-tracing, but they cannot replace it. It only becomes necessary when preventative measures are not enough.

\subsection{Time-boundedness}

Time-boundedness requires that any restrictions on rights and freedoms are temporary and will be lifted within a designated time-frame. The principle of time-boundedness ensures that while some rights may be harmed now, they will not last forever. There is the concern that rights-infringing policies may continue past their usefulness or continue to be used for nefarious purposes. One of the common criticisms of using digital contact-tracing is that it will lead to a permanent change in societal habits and behaviours, with people and governments becoming dependent on them.

Some of the measures used by Korea during the Covid-19 outbreak had clear timelines. For example, all inbound travellers to South Korea were required to download a health app upon arrival in the country and self-quarantine for 14 days, after which, they could delete the app (The Republic of Korea, Cheong Wa Dae, 2020, p. 29) [14]. However, the timeboundedness for digital contact-tracing is a little less clear. Their official announcement in April 2020 stated: "The platform operates on an interim basis, and all the personal data stored in it will be deleted once an official response to COVID-19 is complete" (The Republic of Korea, Cheong Wa Dae, 2020, p. 45).

However, this statement only focusses on the storing of personal data and not necessarily the use of the technology itself, while still being vague about when personal data will be deleted. One of the concerns is that the use of such technologies will exist past the pandemic (Oliver et al., 2020). While Korea has not implemented time-boundedness for their digital contact-tracing, this does not necessarily mean that it is not possible. This could be achieved by limiting its use to:

- Specific dates: This would provide an exact end-point of the use of the technology; for example, after 1 month, 3 months or 6 months.

- The number of new cases: This could be set at a daily threshold, whereby, once it is passed, the use of the digital contact-tracing is implemented and ceased once it is below this number. This could be implemented daily, a daily average or a weekly average. This number should be at an ethically acceptable level so that the use of the technology will not be used indefinitely. It may also be complemented by having a specific cut-off point, as identified in Option 1.

- The number of new deaths: Similar process as described in Option 2, but using the number of deaths as the threshold denominator.

- The total number of active cases: Similar process as described in Option 2, but using the total number of active cases as the threshold denominator. 
IJPCC

16,4

- The virus reproduction rate: Similar process as described in Option 2, but using the reproduction rate as the threshold denominator.

When the Korean Government launched its digital contact-tracing, they probably thought that the outbreak would be short-lived and under control within a few months. However, Covid-19 is an outbreak on a scale that we have not seen before and is set to be with us for the foreseeable future. The consensus seems to point towards 2021 or even 2022 before a vaccine is created (Cortez, 2020), and with no sign of global numbers levelling off, countries are under threat of emergent, if not already growing, outbreaks. Therefore, Korea's "official response to COVID-19" will not end until there is a vaccine or the virus has been eradicated globally.

A possible approach that would accommodate the time-boundedness criteria would be to have a specific cut-off point for its use (e.g. in 3 months from deployment). If there is a clear indication that the outbreak has not subsided or that traditional contact-tracing and other anti-contagion methods are insufficient, then the benefits and harms of digital contacttracing may be re-evaluated and another timeline created (e.g. in an additional 3 months). For example, Norway abandoned their use of digital contact-tracing because numbers were so low and the trade-offs were no longer seen as legitimate. The KCDC needs to be a bit more specific about the timeline of digital contact-tracing and when it no longer fit for purpose.

\section{Conclusion}

The Korean Government learned a lot from the MERS outbreak in 2015 and implemented appropriate measures for the Covid-19 outbreak. It had five years to prepare for the outbreak, which has become apparent in its response compared with other countries. While the KCDC demonstrated how to implement effective action, such as through their use of digital contact-tracing, this does not mean that all countries would do the same. This paper does not endorse blanket acceptability of digital contact-tracing for this reason. If it is used by incompetent, corrupt or nefarious governments and/or institutions, then it is likely to be abused.

This paper demonstrated that traditional contact-tracing is a scientifically effective method, and digital contact-tracing is an additional supplementary tool in pandemic responses. Korea's use of digital contact-tracing was seen as proportionate because of the potentially grave outcomes that were forecast at the start of the outbreak (500,000 deaths), as well the tragic outcomes that materialised in countries such as Spain (27,000 deaths and a three-month lockdown). However, greater efforts need to be made to protect vulnerable groups. For example, by implementing lottery-style testing to ensure the anonymisation of individuals. While the KCDC is the sole organisation permitted access to digital contacttracing data, there needs to be further clarifications made about its use post-coronavirus.

Concerning the principle of necessity, there is no clear-cut method that is both more effective and less intrusive than Korea's use of digital contact-tracing. Lockdowns may be more effective, but they are far more intrusive. Bluetooth corona apps may be less intrusive if implemented correctly but are also less effective. Traditional contact-tracing has effectiveness limitations, so cannot altogether replace digital contact-tracing. While other anti-contagion responses, such as face masks, cannot do the same task as digital contacttracing, so could not effectively replace it.

Unfortunately, there is no clear-cut end-point for Covid-19, which makes it challenging to state how long digital contact-tracing will be needed. This paper proposed the establishment of a specific date cut-off point for its use. Digital contact-tracing should be regularly evaluated to determine if the threat is still credible or if the potential (and actual) 
infringements on rights are excessive, compared to the benefits derived from it. This has already been done Norway, where they abandoned digital contact-tracing because the low case numbers and potential privacy infringements outweighed its benefits.

However, it must be made abundantly clear, that no matter how effective digital contacttracing is, its effectiveness is still fundamentally dependent on a country's ability and resources to act upon this information. For example, they need to have sufficient testing kits, professionals to carry them out, the ability and resources to analyse the samples and all of this should be done in a timely fashion. Korea implemented walk-in and drive-through tests and provided results to individuals within a few hours; which ensured their digital contacttracing was effective. The effectiveness of digital contact-tracing does not exist in a vacuum and is fundamentally reliant on the ecosystem that it is being deployed. Digital contacttracing should not be seen as a silver bullet to bail out poor regulation, shortages of PPE and medical staff and the disregard of epidemiological advice. However, it can not only support but also benefit from, effective policymaking and the myriad of actions required in pandemic response.

\section{Notes}

1. For ease of reference in the paper, I will refer to South Korea simply as "Korea". At no point in the paper do I discuss or refer to North Korea.

2. Please note that Figures 1 and 2 are translated from Korean using Google Translate, so may not be completely accurate.

3. One may also include freedoms, such as employment (with the millions of jobs cut as a result of lockdowns), education (with many schools shutting and either not providing or providing minimal, follow-up education) and the right to participate in the cultural life of the community (unless you make a weak argument that strict Covid-19 lockdown-bonding is a suitable replacement).

4. Both countries had similar rankings the Global Health Security Index (epidemic and pandemic preparedness): Korea was 9th and Spain was 15th (GHS Index 2019).

5. Other reasons include their poor healthcare system and the difficulty of uniting 17 autonomous community healthcare systems contributed to the mismanagement of the outbreak. The country witnessed a great strain on hospital beds, space in ICU units, and the personnel to take care of patients. The previous government implemented cuts to the healthcare system, with many doctors being made redundant, a decrease in available PPE and other equipment. Furthermore, Spain has a high elderly population, who are in the most-at-risk group for Covid-19 deaths. Spain's over 65 population accounts for $18.49 \%$, while South Korea's is a little lower, at $15.92 \%$ (CIA 2020).

6. On $16^{\text {th }}$ March, Spain closed all of its frontiers to non-Spanish citizens. The following day, the Spanish Prime Minister declared a 200bn euro support package (20\% of their annual GDP).

7. Privacy violations; Chilling effect; Social sorting - stereotyping, stigmatisation and discrimination; Paternalism (harm to autonomy); Social fatalism; Behavioural uniformity; Imbalance of distribution of costs; Diminution of trust; Vulnerability; Fear of control; Human error and abuse of power and Fear of being "found out" when hiding legitimate information.

8. I contacted the Korean Government for an exact statistic, but they did not reply to my emails. Therefore, I tried to estimate from a sample size of 100 cases from their website. Out of the 100 cases sample size ( $11^{\text {th }}$ to $18^{\text {th }}$ June), only 35 indicated the use of digital contact-tracing. There was a clear difference in the detail of information provided about travel routes, locations and potential contacts with others (these differences are very apparent when one examines the two types of logs shown in Figures 1 and 2). The total number of cases was 11,225 (Table 1). 
IJPCC 16,4

9. Also known as Church of Jesus, the Temple of the Tabernacle of the Testimony (SCJ) Church of Jesus, the Temple of the Tabernacle of the Testimony (SCJ). The Church is regarded as a cult and people are often hostile towards its members.

10. He tested positive for coronavirus on $6^{\text {th }}$ May.

11. Some propose that coronavirus apps can still be effective with a lower threshold than $60 \%$ (O'Neill, 2020).

12. When I refer to anti-contagion methods, I exclude those that have been previously discussed in this section, namely, lockdowns, traditional contact-tracing and corona apps.

13. Likewise, Korea's digital contact-tracing is only one tool to control their outbreak.

14. If one refuses to install the app or does not submit their daily updates about their health, they will be contacted to do so, until the fourth day of non-compliance, where police are contacted to track the individual down.

\section{References}

Agence France-Presse in Oslo (2020), "Norway suspends Virus-Tracing app due to privacy concerns", The Guardian, 15 June, sec. World news, available at: www.theguardian.com/world/2020/jun/15/ norway-suspends-virus-tracing-app-due-to-privacy-concerns

Agren, D. (2020), "Death of man after face mask arrest shines light on Mexican police brutality", The Guardian, 5 June, sec. World news, available at: www.theguardian.com/world/2020/jun/05/ mexican-arrested-for-not-wearing-face-mask-later-found-dead

American Association for the ICJ (1984), "Siracusa principles on the limitation and derogation provisions in the international covenant on civil and political rights".

Babones, S. (2020), "Countries rolling out coronavirus tracking apps show why they can't work", Foreign Policy (blog), available at: https://foreignpolicy.com/2020/05/12/coronavirus-trackingtracing-apps-cant-work-south-korea-singapore-australia/

Bell, G. (2020), “We need mass surveillance to fight COVID-19 - but it doesn't have to be creepy”, MIT Technology Review, available at: www.technologyreview.com/2020/04/12/999186/covid-19contact-tracing-surveillance-data-privacy-anonymity/

Bock, K.C.R., Kühne, R., Mühlhoff, Měto, R., Ost, J., Pohle, R. and Rehak, (2020), “Data protection impact assessment for the corona app", available at: SSRN 3588172.

Boseley, S. (2020), "WHO expert backtracks after saying asymptomatic transmission 'very rare", The Guardian, 9 June, sec. World news, available at: www.theguardian.com/world/2020/jun/09/whoexpert-backtracks-after-saying-asymptomatic-transmission-very-rare

CDC (2020), "Coronavirus disease 2019 (COVID-19)", Centers for Disease Control and Prevention. 11 February, available at: www.cdc.gov/coronavirus/2019-ncov/php/public-health-recommendations. $\mathrm{html}$

Chandran, R. (2020), "Here's how asia is using tech to tackle COVID-19", World Economic Forum. available at: www.weforum.org/agenda/2020/03/asia-technology-coronavirus-covid19-solutions/

Chung, C. (2020), "The shadowy cult at the center of South Korea's coronavirus outbreak", Coda Story (blog), 26 February, available at: www.codastory.com/waronscience/cult-south-koreacoronavirus/

CIA (2020), "The world Factbook - Central intelligence agency", available at: www.cia.gov/library/ publications/resources/the-world-factbook/

Coffey, H. (2020), “Coronavirus tracking app exposes cheating partners”, The Independent. 14 May, available at: www.independent.co.uk/life-style/love-sex/coronavirus-tracking-app-cheatingpartners-married-south-korea-affair-a9514996.html 
Cohen, I.G., Gostin, L.O. and Weitzner, D.J. (2020), "Digital smartphone tracking for COVID-19: Public health and civil liberties in tension”, JAMA, May. available at: https://doi.org/10.1001/ jama.2020.8570

Cortez, M.F. (2020), "We will be living with the coronavirus pandemic well into 2021”, Bloomberg.Com, 18 June, available at: www.bloomberg.com/news/features/2020-06-18/we-will-be-living-with-thecoronavirus-pandemic-well-into-2021

Cox, D. (2020), "The way South Korea crushed its second wave is a warning to Us all", Wired UK, 26 May, available at: www.wired.co.uk/article/south-korea-coronavirus-response-second-wave

De Ingenieur (2020), “Overheid zoekt app: 5 alarmbellen die afgaan”, De Ingenieur. available at: www. deingenieur.nl/artikel/overheid-zoekt-app-5-alarmbellen-die-afgaan

Dowd, J.B., Rotondi, V., Adriano, L., Brazel, D.M., Block, P., Ding, X., Liu, Y. and Mills, M.C. (2020), "Demographic science aids in understanding the spread and fatality rates of COVID-19", MedRxiv.

Dudley, J.P. and Lee, N.T. (2020), "Disparities in Age-Specific morbidity and mortality from SARS-CoV2 in China and the Republic of Korea", Clinical Infectious Diseases.

Eui-Rae, P. (2020), "Human rights commissioner "corona 19, second concern about excessive disclosure of privacy' | yunhap news”, available at: www.yna.co.kr/view/AKR20200309089000004

European Court of Human Rights (1950), "European convention on human rights",

Ferretti, L., Wymant, C., Kendall, M., Zhao, L., Nurtay, A., Abeler-Dörner, L., Parker, M., Bonsall, D. and Fraser, C. (2020), "Quantifying SARS-CoV-2 transmission suggests epidemic control with digital contact tracing”, Science, Vol. 368 No. 6491, available at: https://doi.org/10.1126/science.abb6936

Fisher, M. and Sang-Hun, C. (2020), "How South Korea flattened the curve", The New York Times, 23 March, sec. World. available at: www.nytimes.com/2020/03/23/world/asia/coronavirus-southkorea-flatten-curve.html

Flaxman, S., Mishra, S., Gandy, A., Unwin, H.J.T., Mellan, T.A., Coupland, H. and Whittaker, C. (2020), "Estimating the effects of Non-Pharmaceutical interventions on COVID-19 in Europe", Nature, June, 1-8. available at: https://doi.org/10.1038/s41586-020-2405-7

Fleming, S. (2020), "South Korea's foreign minister explains how the country contained COVID-19", World Economic Forum. available at: www.weforum.org/agenda/2020/03/south-korea-covid-19containment-testing/

Floridi, L. (2020), "Mind the app - considerations on the ethical risks of COVID-19 apps", Philosophy and Technology, Vol. 33 No. 2, pp. 167-172, available at: https://doi.org/10.1007/s13347-020$00408-5$

Garrett, L. (2020), "COVID-19: the medium is the message", The Lancet, Vol. 395 No. 10228, pp. 942-943.

Garthwaite, R. and Anderson, I. (2020), “Alarm over 'invasive’ Gulf Contact-Tracing apps”, BBC News, 16 June, sec. Middle East. available at: www.bbc.com/news/world-middle-east-53052395

Gayle, C.S., Walker, D.A., Burnton, S., Rourke, A., Sullivan, H., Partington, R. and (2020), D. and Phillips, "Lockdowns reduced infection rate by $81 \%$, research shows - as it happened", The Guardian, 8 June, sec. World news. available at: www.theguardian.com/world/live/2020/jun/08/ coronavirus-live-news-global-cases-near-7-million-as-saudi-infections-pass-100000

Gerards, J. (2013), "How to improve the necessity test of the European court of human rights", International Journal of Constitutional Law, Vol. 11 No. 2, pp. 466-490.

GHS Index (2019), "The global health security index”, GHS Index. available at: www.ghsindex.org/

Gilbert, G.L., Degeling, C. and Johnson, J. (2019), "Communicable disease surveillance ethics in the age of big data and new technology", Asian Bioethics Review, Vol. 11 No. 2, pp. 173-187, available at: https://doi.org/10.1007/s41649-019-00087-1

Golinelli, D., Boetto, E., Carullo, G., Landini, M.P. and Fantini, M.P. (2020), "How the COVID-19 pandemic is favoring the adoption of digital technologies in healthcare: a rapid literature review", MedRxiv. 
IJPCC 16,4

Hauser, A., Counotte, M.J., Margossian, C.C., Konstantinoudis, G., Low, N., Althaus, C.L. and Riou, J. (2020), "Estimation of SARS-CoV-2 mortality during the early stages of an epidemic: a modelling study in Hubei, China and Northern Italy", MedRxiv.

Henley, J. (2020), "We should have done more, admits architect of Sweden's COVID-19 strategy", The Guardian, 3 June, sec. World news, available at: www.theguardian.com/world/2020/jun/03/ architect-of-sweden-coronavirus-strategy-admits-too-many-died-anders-tegnell

Hern, A. (2020), "Nearly one in six Britons would refuse COVID-19 vaccine - survey", The Guardian, 6 July, sec. Media, available at: www.theguardian.com/media/2020/jul/07/almost-one-in-sixbritons-say-would-refuse-covid-19-vaccine

Hsiang, S., Allen, D., Annan-Phan, S., Bell, K., Bolliger, I., Chong, T., Druckenmiller, H., Hultgren, A., Huang, L.Y. and Krasovich, E. (2020), "The effect of Large-Scale anti-Contagion policies on the coronavirus (COVID-19) pandemic", MedRxiv.

Huang, N.E., Qiao, F. and Tung, K.-K. (2020a), “A Data-Driven tool for tracking and predicting the course of COVID-19 epidemic as it evolves", MedRxiv.

Huang, Y., Sun, M. and Sui, Y. (2020b), "How digital contact tracing slowed COVID-19 in East Asia", Harvard Business Review, 15 April, available at: https:/hbr.org/2020/04/how-digital-contacttracing-slowed-covid-19-in-east-asia

Hui, M. (2020), "If Seoul falls, the country falls': South Korea is moving fast to quash a new COVID-19 cluster", Quartz, available at: https://qz.com/1855878/8000-police-in-south-korea-mobilized-toquash-itaewon-covid-19-cluster/

Hurka, T. (2005), "Proportionality in the morality of war", Philosophy Public Affairs, Vol. 33 No. 1, pp. 34-66.

Hurka, T. (2008), "Proportionality and necessity".

Jo, E.A. (2020), "South Korea's experiment in pandemic surveillance”, Available at: https://thediplomat. com/2020/04/south-koreas-experiment-in-pandemic-surveillance/

Jones, S. and Willsher, K. (2020), "Germany and France reopen borders as Europe emerges from lockdown", The Guardian, 15 June, sec. World news, available at: www.theguardian.com/world/ 2020/jun/15/germany-and-france-reopen-borders-as-europe-emerges-from-lockdown

Joseph, S. (2020), "COVID 19 and human rights: past, present and future”, SSRN Scholarly Paper ID 3574491: Social Science Research Network. Rochester, New York, NY Available at: https://doi. org/10.2139/ssrn.3574491

Kang, Y.J. (2020), "Characteristics of COVID-19 infection in Korea from the mass infection perspective”, Journal of Preventive Medicine and Public Health, Vol. 53 No. 3.

Kasulis, K. (2020), "S Korea's smartphone apps tracking coronavirus won't stop buzzing”, Al Jazeera, available at: www.aljazeera.com/news/2020/04/korea-smartphone-apps-tracking-coronaviruswon-stop-buzzing-200408074008185.html

Keeling, M.J., Hollingsworth, T.D. and Read, J.M. (2020), "The efficacy of contact tracing for the containment of the 2019 novel coronavirus (COVID-19). | MedRxiv", MedRxiv. 17 February, Available at: www.medrxiv.org/content/10.1101/2020.02.14.20023036v1

Kim, B. (2020a), "Lessons for America: How South Korean authorities used the law to fight the coronavirus", Lawfare. 16 March, available at: www.lawfareblog.com/lessons-america-howsouth-korean-authorities-used-law-fight-coronavirus

Kim, C. (2020b), "Half of South Korea's coronavirus cases are linked to a controversial religious organization", Vox. 22 February, Available at: www.vox.com/2020/2/22/21148477/coronavirussouth-korea-shincheonji-church-jesus

Kim, M.S. (2020c), "Seoul's radical experiment in digital contact tracing", The New Yorker, available at: www.newyorker.com/news/news-desk/seouls-radical-experiment-in-digital-contact-tracing

Kim, N. (2020d), "Anti-Gay backlash feared in South Korea after coronavirus media reports", The Guardian, 8 May, sec. World news, available at: www.theguardian.com/world/2020/may/08/antigay-backlash-feared-in-south-korea-after-coronavirus-media-reports 
Kim, S. (2020e), "How South Korea lost control of its coronavirus outbreak", The New Yorker, available at: www.newyorker.com/news/news-desk/how-south-korea-lost-control-of-its-coronavirusoutbreak

Kim, V. (2020f), "Were you on this bus with a coronavirus patient? South Korea is on the hunt for infections", Los Angeles Times. 27 February, available at: www.latimes.com/world-nation/story/ 2020-02-27/south-korea-coronavirus-cases-surveillance

Kim, D. and Kim, D. (2020), “There's an app for that': Use of COVID-19 apps in Singapore and South Korea", Asia Pacific Foundation of Canada, available at: www.asiapacific.ca/publication/theresapp-use-covid-19-apps-singapore-and-south-korea

Klinkenberg, D., Fraser, C. and Heesterbeek, H. (2006), “The effectiveness of contact tracing in emerging epidemics", PloS One, Vol. 1 No. 1.

Klonowska, K. (2020), The COVID-19 Pandemic: Two Waves of Technological Responses in the European Union, The Hague Centre for Strategic Studies. The Hague.

Kola, O. (2020), "Nigeria: Commission claims 18 killed in virus lockdown", Available at: www.aa.com.tr/ en/africa/nigeria-commission-claims-18-killed-in-virus-lockdown/1806639

Kretzschmar, M.E., Rozhnova, G. and van Boven, M. (2020), "Isolation and contact tracing can tip the scale to the containment of COVID-19 in populations with social distancing", MedRxiv, April, 34.

Lee, D. (2020), "Mounting anger in South Korea over secretive sect at outbreak epicenter", South China Morning Post, available at: www.scmp.com/week-asia/health-environment/article/3052550/ south-korea-mounting-anger-rumours-over-shincheonji

McMurtry, A. and Zampano, G. (2020), “COVID-19: What went wrong in Italy and Spain?”, Available at: www.aa.com.tr/en/europe/covid-19-what-went-wrong-in-italy-and-spain/1797461

Macnish, K. (2015), "An eye for an eye: Proportionality and surveillance", Ethical Theory and Moral Practice, Vol. 18 No. 3, pp. 529-548.

Mauro, A. (2020), “Coronavirus contact tracing poses serious threats to our privacy”, The Conversation, available at: http://theconversation.com/coronavirus-contact-tracing-poses-serious-threats-toour-privacy-137073

Ministry of Land, Infrastructure, and Transport (2020), "Foreign Q\&A".

Mizumoto, K., Kagaya, K. and Chowell, G. (2020), "Early epidemiological assessment of the transmission potential and virulence of coronavirus disease 2019 (COVID-19) in Wuhan city: China, January-February, 2020", MedRxiv.

Morley, J., Cowls, J., Taddeo, M. (2020), and L. and Floridi, "Ethical guidelines for SARS-CoV-2 digital tracking and tracing systems”, SSRN Scholarly Paper ID 3582550: Social Science Research Network. Rochester, New York, NY, available at: https://doi.org/10.2139/ssrn.3582550

Mugabi, I. (2020), "COVID-19: security forces in Africa brutalizing civilians under lockdown | DW | 20.04.2020", DW.COM, available at: www.dw.com/en/covid-19-security-forces-in-africabrutalizing-civilians-under-lockdown/a-53192163

Muller, C. et al. (2020), "Wetenschappers En experts aan kabinet: 'geen Corona-Apps zonder waarborgen voor grondrechten En aandacht voor maatschappelijke implicaties”, ALLAI. 13 April, available at: https://allai.nl/wetenschappers-en-experts-aan-kabinet-geen-corona-appszonder-waarborgen-voor-grondrechten-en-aandacht-voor-maatschappelijke-implicaties/

National Human Rights Commission of Korea (2020), “NHRCK's COVID-19 response | national human rights commission of korea", Available at: www.humanrights.go.kr/site/program/board/ basicboard $/$ view?currentpage $=3 \&$ menuid $=002006006 \&$ pagesize $=10 \&$ boardtypeid $=7057 \&$ boardid $=7605328$

Neal, K. (2020), "As an epidemiologist, I know how well contact tracing could work for coronavirus | Keith neal”, The Guardian, 15 May, sec. Opinion, available at: www.theguardian.com/ commentisfree/2020/may/15/epidemiologists-contact-tracing-coronavirus 
IJPCC

16,4

Normile, D. (2020), “Coronavirus cases have dropped sharply in South Korea. What's the secret to its success?”, Science | AAAS. 17 March, Available at: www.sciencemag.org/news/2020/03/ coronavirus-cases-have-dropped-sharply-south-korea-whats-secret-its-success

O'Hagan, S. (2020), "Health experts on the psychological cost of COVID-19", The Guardian, 7 June, sec. World news, available at: www.theguardian.com/world/2020/jun/07/health-experts-on-thepsychological-cost-of-covid-19

Oliver, N., Lepri, B., Sterly, H., Lambiotte, R., Delataille, S., Nadai, M.D., Letouzé, E., Salah, A.A., Benjamins, R. and Cattuto, C. (2020), Mobile Phone Data for Informing Public Health Actions across the COVID-19 Pandemic Life Cycle, American Association for the Advancement of Science Washington, DC.

O'Neill, P.H. (2020), "No, coronavirus apps don't need 60\% adoption to be effective”, MIT Technology Review, available at: www.technologyreview.com/2020/06/05/1002775/covid-apps-effective-atless-than-60-percent-download/

Park, S., Choi, G.J. and Ko, H. (2020), "Information technology-based tracing strategy in response to COVID-19 in South Korea-privacy controversies”, JAMA, Vol. 323 No. 21, pp. 2129-2130, Available at: https://doi.org/10.1001/jama.2020.6602

Pietrewicz, O. (2020), "Preparedness and surveillance: South Korea’s response to COVID-19",

Ratcliffe, R. (2020), "Teargas, beatings and bleach: the most extreme COVID-19 lockdown controls around the world", The Guardian, 1 April, sec. Global development, available at: www. theguardian.com/global-development/2020/apr/01/extreme-coronavirus-lockdown-controlsraise-fears-for-worlds-poorest

Realmeter (2020), “신천지 압수수색 여부, 찬성 $86.2 \%$ vs 반대 $6.6 \%$, 리얼미터 - Realmeter (blog), available at: www.realmeter.net $\%$ ec $\% 8 \mathrm{~b} \% \mathrm{a} 0 \% \mathrm{ec} \% \mathrm{~b} 2 \% 9 \mathrm{c} \% \mathrm{ec} \% \mathrm{a} 7 \% 80-\% \mathrm{ec} \% 95 \% 95 \% \mathrm{ec} \%$ $88 \% 98 \%$ ec $\% 88 \% 98 \%$ ec $\% 83 \% 89-\%$ ec $\% 97 \%$ ac $\%$ eb $\%$ b6 $\% 80-\%$ ec $\%$ b0 $\%$ ac $\%$ ec $\% 84 \%$ b1-862 -vs- $\%$ eb $\%$ b0 $\% 98 \%$ eb $\% 8 c \% 80-6-6 /$

Samarajiva, I. (2020a), “The Korean playbook for COVID-19 (translated)”, Medium. 7 April, Available at: https://medium.com/@indica/the-korean-playbook-for-covid-19-translated-c726aa21c0a3

Samarajiva, I. (2020b), "How Korea does contact tracing", Medium. 5 April, available at: https:// medium.com/@indica/how-korea-does-contact-tracing-1b2662b5b894

Samarajiva, I. (2020c), "How Germany is a COVID failure", Medium. 21 April, Available at: https:// medium.com/@indica/germany-is-a-coronavirus-failure-7e2a58f5b4fe

Sandford, A. (2020), "Coronavirus: Half of humanity on lockdown in 90 countries”, Euronews. 2 April, available at: www.euronews.com/2020/04/02/coronavirus-in-europe-spain-s-death-toll-hits-10000-after-record-950-new-deaths-in-24-hou

Sang-Hun, C. (2020), "Proselytizing robots': inside South Korean church at outbreak's center", The New York Times, 10 March, sec. World, available at: www.nytimes.com/2020/03/10/world/asia/southkorea-coronavirus-shincheonji.html

Seibt, S. (2020), "South Korea seeks criminal charges against Christian sect over coronavirus spread", France 24, 3 March 3, available at: www.france24.com/en/20200303-south-korea-seeks-criminalcharges-against-christian-sect-over-coronavirus-spread

Seoul News (2020), “코로나19 확진자 이동경로”, 8 June, available at: http://news.seoul.go.kr/welfare/ archives $/ 513105$

SeungCheol, O. (2020), "The strategy of tracking travel history of infected persons to make public and ImposeQuarantine measures", Oxford university MPP and SciencesPo MPA, available at: https://covidtranslate.org/tracking-strategy-in-Korea.pdf

Shaw, R., Kim, Y-K. and Hua, J. (2020), "Governance, technology and citizen behavior in a pandemic: Lessons from COVID-19 in East Asia”, Progress in Disaster Science, Vol. 6, pp. 100090.

Shim, E., Tariq, A., Choi, W., Lee, Y. and Chowell, G. (2020), "Transmission potential and severity of COVID-19 in South Korea”, International Journal of Infectious Diseases, Vol. 93 
Son, K.-B., Lee, T.-J. and Hwang, S-S. (2020), "Does the health system's response matter to cope with the COVID-19 outbreak? recent evidence from South Korea",

Statista (2020), "South Korea: Shincheonji church-related COVID-19 cases 2020", Statista, available at: www.statista.com/statistics/1103080/south-korea-covid-19-cases-related-to-shincheonji-church/

Taddeo, M. (2020), "The ethical governance of the digital during and after the COVID-19 pandemic", Minds and Machines, Vol. 30 No. 2, Available at: https://doi.org/10.1007/s11023-020-09528-5

The Republic of Korea, Cheong Wa Dae (2020), "How Korea responded to a pandemic using ICT flattening the curve on COVID 19", Available at: https://www1.president.go.kr/petitions/585290

United Nations (1966), "United nations international covenant on civil and political rights",

United Nations General Assembly (1948), "Universal declaration of human rights”, Available at: www. un.org/en/universal-declaration-human-rights/

Ward, A. (2020), "How Spain's coronavirus outbreak got so bad so fast", Vox. 20 March, Available at: www.vox.com/2020/3/20/21183315/coronavirus-spain-outbreak-cases-tests

Whitworth, J. (2020), “Coronavirus: Why testing and contact tracing isn't a simple solution”, The Conversation, available at: http://theconversation.com/coronavirus-why-testing-and-contacttracing-isnt-a-simple-solution-137214

Woodward, A. (2020), "South Korea just flexed its Contact-Tracing power: after partiers with the coronavirus went to nightclubs, it found and tested 46,000 exposed people", Business Insider, available at: www.businessinsider.com/south-korea-contact-tracing-helped-control-nightcluboutbreak-2020-5

World Health Organisation (2020), "Coronavirus disease 2019 (COVID-19) situation report - 73”, Available at: www.who.int/docs/default-source/coronaviruse/situation-reports/20200402-sitrep73-covid-19.pdf?sfvrsn=5ae25bc7_4

Wray, S. (2020), "South Korea to step-up online coronavirus tracking”, Smart Cities World, available at: www.smartcitiesworld.net/news/news/south-korea-to-step-up-online-coronavirus-tracking-5109

Yonhap News Agency (2019), "S. Korea tops smartphone penetration rate in 2018: Report", Yonhap News Agency. 6 February, available at: https://en.yna.co.kr/view/AEN20190206001200325

Zastrow, M. (2020), "South Korea is reporting intimate details of COVID-19 cases: Has it helped?", Nature, Available at: https://doi.org/10.1038/d41586-020-00740-y

\section{Corresponding author}

Mark Ryan can be contacted at: mryan@kth.se

For instructions on how to order reprints of this article, please visit our website:

www.emeraldgrouppublishing.com/licensing/reprints.htm

Or contact us for further details: permissions@emeraldinsight.com 